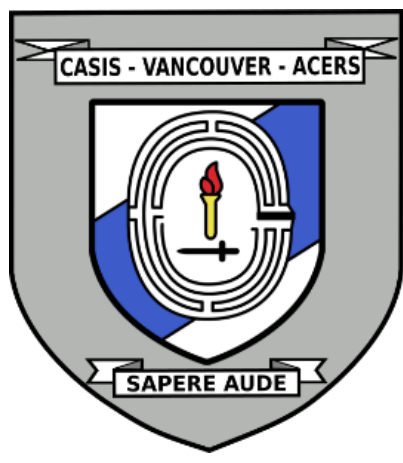

\title{
AUTHENTICITY, ADVERSITY \& ACCOUNTABILITY IN THE CONTEXT OF UNIFORMED LEADERSHIP
}

Date: November 26, 2021

Disclaimer: This briefing note contains the encapsulation of views presented by the speaker and does not exclusively represent the views of the Canadian Association for Security and Intelligence Studies.

\section{KEY EVENTS}

On November 26, 2021, Commander Jonathan A. Kouwenberg from the Royal Canadian Navy, presented Authenticity, Adversity and Accountability in the Context of Uniformed Leadership at the 2021 CASIS West Coast Security Conference. The presentation depicted the overarching characteristics of what comprises strong leadership, primarily the presence that leaders bring; methods of communication; and creating a culture of resiliency, accountability, and trust. Commander Kouwenberg's presentation was followed by a question and answer period to allow conference attendees the opportunity to engage directly with panelists.

\section{NATURE OF DISCUSSION}

\section{Presentation}

Over the course of his presentation, Commander Kouwenberg illustrated the multifarious nature of a good leader, including aspects like valuing the process with which one reaches success, rather than just the success itself; connecting with one's team as individuals; and communicating consistently, clearly, and with emphasis on positive messaging. Primary points of the presentation emphasized that authentic leadership requires constant self-reflection, accountability, and the ability to overcome adversity. Further, authentic leaders will work to create an environment where the entire team feels valued and operates in an atmosphere of trust. 


\section{Question Period}

During the question and answer period, Commander Kouwenberg discussed the issue of having leaders who view themselves as outside the boundaries of ethics. Skills that leaders can develop to aid them in leading during challenging times were also discussed.

\section{BACKGROUND}

\section{Presentation}

Commander Kouwenberg's presentation began by addressing that authentic leadership is dynamic and requires constant re-evaluation of oneself, one's team, and the overall objective. Exploring and reflecting on the internal reasons why one wants to become a leader and give directions to others will help one discern how equipped they are to become a leader. Continuous self-reflection will lead to succinct priorities as a leader. Commander Kouwenberg expressed the nature in which an authentic leader can transpose the goals and objectives of their organization in order to be able to communicate them to one's team with personal conviction. Leaders will be given certain organizational lines to prioritize. By finding ways to speak to these goals with one's own voice and have them ring true to oneself, a leader will garner more 'buy in' and support from their team. Although leaders in uniform are practicing leadership in a work environment, this leadership is accompanied with the responsibility to cultivate a family-like culture and unlimited liability one hundred percent of the time.

Authentic leadership is manifold in nature. Commander Kouwenberg's presentation worked to highlight the various traits and practices that can be embodied to attain strong leadership skills. An authentic leader is one that is accountable to the process of arriving at success, not solely the success or the end goal itself. Rather than focusing on the 'presents' that accompany success, like medals or money, Commander Kouwenberg encouraged leaders to focus on their 'presence,' as a leader. Leaders will engage with those on their team as individuals, rather than generalizing or essentializing the people as merely a part in what comprises the whole. Although it takes more time to engage with each person individually, this will allow leaders to have a stronger connection with their team which will in turn help the goals of the organization in the long run. Leaders that connect with their team are less likely to stereotype and box individuals with constraints that limit their potential. 
The methods and practices with which one communicates can either denigrate or enable authentic leadership. Authentic leaders acknowledge when mistakes have been made and apologize in a direct and public manner. In turn, authentic leaders practice gratitude and appreciate people. They communicate messages with persistence and repetition to ensure it is understood. In addition, leaders should utilize positive communication because individuals are often more inclined to remember only the negative aspects of communication. However, effective communication also allows space for people to process and does not over inundate others with too much information. An excess of positive communication runs the risk of being interpreted as 'white washing'.

Overcoming adversity is a fundamental part of authentic leadership that should be approached with patience and a willingness to compromise. Facing compromise is a reality of uniformed leadership and it should be acknowledged that one's personal understanding of success may differ from that of one's superior. For example, the quantitative outcome of a certain objective may be used as the measure of success for some, whereas the qualitative nature of an effective and cohesive team may constitute success for others.

Authentic leadership requires accountability. When accountability for one's role is not instilled as an expectation for those of all ranks in the organization, the line becomes blurry, and this mentality can creep up in the organization as individuals gain rank. Additionally, being accountable means that one needs to be aware of their reputation, both internally in the organization and externally, on social media, for example. As one spends more time within an organization, there is an accumulating portfolio of decisions, actions, and attitudes that comprises one's reputation.

While developing a team, Commander Kouwenberg iterated that leaders should aim to engage their team in 'type 2 fun'. On the 'fun' scale, type 1 fun is enjoyable both during and after it takes place, a team barbeque, for example. Whereas type 3 fun is neither enjoyable in the moment nor in retrospect. Commander Kouwenberg asserts that leaders in uniform should aim for type 2 fun, which builds the cohesiveness of a team and challenges them to learn from adversity. Type 2 fun provides a middle ground between fun that does not serve a higher purpose and fun that may put the team in a situation that is beyond what challenges them in a beneficial way. Type 2 fun engages a team in an effort that allows for feedback, learning, and growth.

During his presentation, Commander Kouwenberg illustrated a story wherein a sailor with a lower rank asked permission to provide a report to the officer driving 
the ship about other vessels that were to come within a certain vicinity of their ship. The decision of the leader to either hear the report or not sends a message to the lower ranking sailor about whether the job they are doing is important and whether they are a valuable member of the team. A strong leader will consider when it is important to engage with the report so as to involve these lower down members of the team and demonstrate that each person's role in the team is valued.

Commander Kouwenberg's presentation used another story to illustrate that authentic leaders are equally a part of the team as any other member and the importance of fostering trust early on. During the height of COVID-19, sailors were required to isolate themselves in a hotel room for two weeks prior to boarding the ship. When one sailor asked their captain whether they would also be quarantining, this illustrated a deficit of trust that the leader would also be abiding by the same rules put in place for the rest of the team. Rather than rising above the rules, this captain had intended that everybody would quarantine, including himself. Although the team referenced in this story may have been a strong team in other regards, this query demonstrates a lack of trust that the entirety of the team, including the captain, would be held to the same standards. Commander Kouwenberg used this story to iterate that trust is amassed when a leader communicates openly, listens genuinely to their team, and is involved. Trust needs to be developed ahead of time, rather than in the middle of an operation when circumstance requires trust among team members. Leaders will not garner trust merely because they are in a position of authority. Trust needs to be earned.

\section{Question Period}

When asked about ethical behaviour and corruption in leadership, Commander Kouwenberg expressed what he termed a crisis regarding what constitutes a moral or ethical leader. He highlighted a phenomenon he has noticed in recent years whereby some uniformed military leaders do not remember that rules of ethics apply to them because of their position of authority. This is not a problem solely in the military - it can breach other contexts as well. Commander Kouwenberg illustrated that the root of the problem may be how we choose individuals for high-level leadership positions and the accompanying characteristics of individuals that fill these offices. The type of individual brought forward for these roles often have qualities akin to megalomania, force of will, and strong self-assurance. In turn, this may be accompanied by the belief that leaders are above the common structures of ethical boundaries. Commander Kouwenberg expressed his concern for the propensity for leaders as they ascend 
in rank, to forget that rules and ethics also apply to them. Acknowledging that there is not an easy solution, Commander Kouwenberg iterated that the importance of continuing the conversation about more feminine or alternative approaches to leadership to ensure checks and balances are in place to enable moral leadership.

The audience asked what kind of skill set would enable leaders to overcome their own challenges in order to provide strong leadership even in challenging times. Commander Kouwenberg encouraged having structures or models in place that one can draw upon in trying times to reflect and stay on track. Putting emphasis on models grounded in leadership theory provides current and future leaders with the resources to apply these frameworks to any number of challenging responsibilities or contexts they might encounter. In addition, Commander Kouwenberg stressed the importance of setting and communicating one's mission in order to stay on track.

\section{KEY POINTS OF DISCUSSION}

\section{Presentation}

- Authentic leaders focus on the process with which success is reached, not the material outcomes of said success.

- Leaders communicate persistently and positively and from a place of personal conviction, accept when mistakes have been made, and connect with their team on an individual level.

- Leadership requires accountability and the ability to overcome adversity.

- Leaders in uniform should aim for type 2 fun, which enables growth and group cohesion.

- You cannot 'surge' trust when you find yourself needing it. It needs to be developed and practiced ahead of time.

\section{Question Period}

- Leaders that have a strong vision and self-assured nature may also view themselves as above ethical boundaries. To combat this, we might explore more alternative approaches to leadership or develop stronger check systems to avoid such instances of leaders seeing themselves as above structures of ethics.

- Being a patient leader is easy when life is easy but having models of leadership based in theory allows individuals to draw upon them in challenging times.

The Journal of Intelligence, Conflict, and Warfare

Volume 4, Issue 3 
- Leaders should set clear mission statements in order to illustrate a clear idea for themselves and others what the intended goal is.

(C) (JONATHAN A. KOUWENBERG, 2022)

Published by the Journal of Intelligence, Conflict, and Warfare and Simon Fraser University

Available from: https://jicw.org/ 